\title{
Evaluation of Genotoxicity by Micronucleus Assay in vitro and by Allium cepa Test in vivo
}

\author{
Christina N. Banti* and Sotiris K. Hadjikakou*
}

Section of Inorganic and Analytical Chemistry, Department of Chemistry, University of Ioannina, 45110 loannina, Greece

*For correspondence: cbanti@uoi.gr; shadjika@uoi.gr

\begin{abstract}
[Abstract] The in vitro and in vivo genotoxicity of new metallodrugs either as Small Bioactive Molecules (SBAMs) or Conjugates of Metals with Drugs (CoMeDs) is evaluated by the micronucleus test and the Allium cepa assay, respectively. Fetal lung fibroblast cells (MRC-5), normal human corneal epithelial cells (HCEC) and immortalized human keratinocytes cells (HaCaT) were incubated with solutions of SBAMs or CoMeDs at their $\mathrm{IC}_{50}$ values for $48 \mathrm{~h}$ (the concentration of a compound which is required to inhibit the cells growth by $50 \%$ in relation to the non-treated cells). The micronucleus abundance percentage towards the corresponding one, of the non-treated cells indicates the in vitro genotoxicity of the formulations. The in vivo Allium cepa test comprises the exposing of the plant Allium cepa roots to an SBAMs or a CoMeDs solution for $48 \mathrm{~h}$. The percentages of the mitotic index, the chromosome aberrations, the nuclear abnormalities and the presence of the micronucleus are calculated indicating the in vivo genotoxicity of the agent.
\end{abstract}

Keywords: Biological inorganic chemistry, Genotoxicity, Micronucleus, Allium cepa, Mitotic index, Metallodrug, Compound

[Background] Inorganic biochemistry, biological inorganic chemistry or bioinorganic chemistry is a multidiscipline scientific field which combines biological inorganic chemistry, biochemistry, biology, medicinal chemistry, microbiology and other fields (Latsis et al., 2018). Nowadays, the research on the design and development of new metallodrugs [Small Bioactive Molecules (SBAMs) or Conjugates of Metals with Drugs (CoMeDs)] against numerous cancer types, includes their biological activity towards cancerous and non cancerous models (Banti et al., 2016; Sainis et al., 2016; Banti et al., 2018; Chrysouli et al., 2018a and 2018b; Latsis et al., 2018; Milionis et al., 2018; Stathopoulou et al., 2018; Banti et al., 2019; Polychronis et al., 2019). Especially, the development of new SBAMs or CoMeDs imposes the need to assess their potential in vitro and in vivo toxicity against experimental models in order to check their potential risks (Banti et al., 2016; Sainis et al., 2016; Banti et al., 2018; Chrysouli et al., 2018a and 2018b; Latsis et al., 2018; Milionis et al., 2018; Stathopoulou et al., 2018; Banti et al., 2019; Polychronis et al., 2019). Therefore, the micronucleus assay has been developed in monitoring genetic damage in normal human cells as it is a sensitive tool for toxicity screening and it is capable in reducing the use of animals in toxicological testing (Sahu et al., 2014). The presence of micronucleus (MN) is a biomarker of mutagenic, genotoxic, or teratogenic agent influence (Torres-Bugarín et al., 2014). The in vitro genotoxicity is calculated by checking the micronucleus frequency, upon treatment of normal cells by an agent at the concentration of its $I_{50}$ value (Chrysouli et al., 2018a and 2018b; 
Latsis et al., 2018; Milionis et al., 2018; Sainis et al., 2016; Stathopoulou et al., 2018). The Allium cepa test, on the other hand, is an in vivo experimental model which is employed to evaluate the potential genotoxicity in vivo. Allium cepa displays high correlation with mammal test systems (Sainis et al., 2016; Chrysouli et al., 2018a and 2018b; Milionis et al., 2018; Stathopoulou et al., 2018). The assay is useful to identify the damaging effect or to evaluate the influence of a metallodrug at different concentrations (Sainis et al., 2016; Chrysouli et al., 2018a and 2018b; Milionis et al., 2018; Stathopoulou et al., 2018). The mitotic index (\%) and DNA damages such as chromosomal aberrations (\%), nuclear abnormalities (\%) and micronucleus (\%) are calculated when roots of Allium cepa are treated with different concentrations of a metallodrug for $48 \mathrm{~h}$.

\section{Materials and Reagents}

A. Micronucleus assay

1. Latex gloves (KCWW, Kimberly-Clark, catalog number: 57330)

2. Pipette tips (Sterile)

3. $100 \mathrm{~mm}$ Petri dishes (SARSTEDT, catalog number: 83.3902), mammalian cell culture containers for adherent cells

Note: Any other Petri dishes or flask suitable for your cell line may work.

4. Microscope slides (UltiDent Scientific, catalog number: 170-7107A) Note: Any microscope slide that fits on your microscope can be used.

5. Cover glass (UltiDent Scientific, catalog number: 170-C1818) Note: Any cover glass can be used. The best cover glasses are the \#1.5; however \#1.0 or \#0 may be used if high quality images are not required.

6. 6-well tissue culture treated plate (Corning, catalog number: 3506 )

7. 24-well tissue culture plate (Corning, catalog number: 3524 )

8. Mammalian non cancerous adherent cells, for example, MRC-5, HCEC, HaCaT cells, etc.

9. Required complete culture media

a. DMEM (WISENT, catalog number: 319-005-EL)

Note: The growth medium is adapted for each cell line. Verify with the cell line suppliers to determine the optimal growth medium for the cells and the necessary supplements.

b. Fetal bovine serum (FBS) (WISENT, catalog number: 095150)

Note: Usually, a $10 \% \mathrm{v} / \mathrm{v}$ solution is used, but some cell lines will require different concentrations. See with your cell line supplier.

c. Penicillin/streptomycin (WISENT, catalog number: 450-201-EL)

Note: It is usually supplied as a 100x stock and therefore must be diluted 1:100 in DMEM.

d. L-glutamine (Sigma-Aldrich, catalog number: G3126)

10. Trypsin $\left(0.05 \%\right.$ or $0.25 \%$ in PBS) (Thermo Fisher Scientific, Gibco ${ }^{\mathrm{TM}}$, catalog number: 25200072)

11. Phosphate buffer saline (PBS, 1x) (Sigma-Aldrich, catalog number: P-4417) 
12. Potassium chloride (KCl) (Sigma-Aldrich, catalog number: P9541)

13. Acetic acid (Sigma-Aldrich, catalog number: 320099)

14. Methanol (Sigma-Aldrich, catalog number: 34860)

15. Acridine orange (Sigma-Aldrich, catalog number: A8097)

16. $70 \%$ ethanol

17. Metallodrugs (at $I C_{50}$ values)

18. FBS

\section{B. Allium cepa assay}

1. Onions bulbs (Allium cepa), approximately $1.5-2.0 \mathrm{~cm}$ in diameter

2. Razor blades

3. Pipette tips

4. Glass microscope slide $(75 \times 25 \mathrm{~mm})$ (VWR, catalog number: $48300-025)$

5. Coverslips (Fisher Scientific, catalog number: 12-543D)

6. Eppendorf tubes $1.5 \mathrm{ml}$ (VWR, catalog number: 89000-028)

7. Test tubes (10 ml) (BOROSIL, catalog number: 9820U04)

8. Pencil with an eraser

9. Nail polish (nitrocellulose dissolved in butyl and ethyl acetate)

10. Double distilled water $\left(\mathrm{ddH}_{2} \mathrm{O}\right)$, standard for highly purified laboratory water for biochemical experiments.

11. Hydrochloric acid (e.g., Merck, catalog number: HX0603-75)

12. Acetic acid (e.g., Merck, catalog number: AX0073-6)

13. Schiff's reagents (HiMedia Laboratories, catalog number: S074-500ML)

14. Nail polish

\section{Equipment}

A. Micronucleus assay

1. Laminar flow hood

2. Hemocytometer

3. Pipettes (any pipettes will do)

4. Incubator (any incubator is fine if it maintains $5 \% \mathrm{CO}_{2}$ and moisture)

5. Fluorescent microscope (Nikon Instruments, model: Eclipse E800) with highly sensitive camera (ANDOR, model: Zyla 5.5) controlled by Nikon NIS-Elements software

\section{B. Allium cepa assay}

1. Incubator

Note: Any incubator is fine if it maintains $25{ }^{\circ} \mathrm{C}$ and $37{ }^{\circ} \mathrm{C}, 50-60 \%$ humidity and $12 \mathrm{~h}$ day lighting/ $12 \mathrm{~h}$ dark for $48 \mathrm{~h}$. 
2. Light microscope (Olympus, 10x objective)

3. Digital camera (Nikon, model: COOLPIX P100, 10.3 megapixel, 26x zoom)

\section{Software}

1. For both Micronucleus assay and Allium cepa assays: Microsoft Office Excel

\section{Procedure}

A. Micronucleus assay

1. Cell preparation

a. Culture the cells according to their requirement (e.g., MRC-5, HCEC, HaCaT cell lines, etc.).

b. Remove medium, and then twice rinse cells with $10 \mathrm{ml}$ PBS, removing the PBS after each washing. The PBS should be autoclaved before use.

c. Add $1 \mathrm{ml} 0.25 \%$ trypsin to the cells and incubate at $37^{\circ} \mathrm{C}$ for $1-5 \mathrm{~min}$ until the cells appear round.

d. Add $10 \mathrm{ml}$ culture medium with $10 \%$ FBS, and detach the cells by pipetting.

e. Count the cells using a hemocytometer.

Note: A relatively accurate number of cells each time is crucial.

f. Prepare desired seeding concentration, and then seed cell into dishes or 6-well plates.

2. Growing cells on cover glasses

Harvest cells and plate an appropriate number of cells per dish or per well in a 6-well plate, at least in duplicate in a final volume of culture medium $1 \mathrm{ml}$. The number of cells for seeding should be determined by the aggressiveness of the treatment. For example, MRC- 5 cells are seeded at a density of $2 \times 10^{4}$ cells/well and HCEC cells seeded at a density of $15 \times 10^{4}$ cells/well; Incubate cells for $24 \mathrm{~h}$ in a $\mathrm{CO}_{2}$ incubator at $37^{\circ} \mathrm{C}$ and allow them to attach to the plate/dish.

a. Before the plating, place the sterile cover glasses slip flat into each well of a 6-well plate.

Notes:

i. We usually put one coverglass in one well of the 24-well plate; or no more than 2 coverglasses in one well of the 6-well plate, or no more than 5 cover glasses in a $60 \mathrm{~mm}$ dish.

ii. Pipette up and down or shake the dish to make sure cells are not concentrating in the center of the dish well. Make sure there are no air bubbles between the coverglasses and the tissue culture dish.

b. Treat the cells as necessary with the metallodrugs (at their $\mathrm{IC}_{50}$ values, against immortalized non-cancer cells).

c. Incubate the cells in a $\mathrm{CO}_{2}$ incubator at $37^{\circ} \mathrm{C}$ for $48 \mathrm{~h}$.

3. Fixation and staining 
Note: The solutions in washing fixation or staining steps are gently handled.

a. Remove the culture medium after $48 \mathrm{~h}$, and then rinse the cells three times each with $3 \mathrm{ml}$ PBS.

b. Remove PBS and add $2-3 \mathrm{ml}$ of a hypotonic solution $(75 \mathrm{mM} \mathrm{KCl})$ solution and leave the dishes/plates at room temperature (RT) for $10 \mathrm{~min}$.

c. Remove the $\mathrm{KCl}$, the cells will be fixed by at least three changes of $1 / 3$ acetic acid/methanol with fast rinse procedure. Repeat the procedure three times. Remove the solution of acetic $\mathrm{acid} / \mathrm{methanol}$ and the cover slips will be also washed with cold methanol containing $1 \%$ acetic acid.

d. Add $3 \mathrm{ml}$ of acridine orange solution $\left(5 \mathrm{\mu g} \mathrm{ml}^{-1}\right)$ and incubate for $15 \mathrm{~min}$ at $37^{\circ} \mathrm{C}$.

e. Remove the acridine orange, and the cover slips will be rinsed three times each with $3 \mathrm{ml}$ PBS to remove any excess acridine orange stain.

f. Get the cover slip from the well and put it face down on the drop of PBS, push it tightly and attach to the glass slide.

g. The slide now is ready to observe under a fluorescence microscope.

\section{B. Allium cepa assay (Figure 1)}

1. Purchase fresh onion bulbs (Allium cepa, $\sim 1.0-1.5 \mathrm{~cm}$ in diameter) from a local grocery store.

2. Remove and discard the outermost dry, brown layers without destroying the root primordia.

3. Place the bulbs of Allium cepa on test tubes $(10 \mathrm{ml})$ containing double distilled water.

4. Place the test tubes in an incubator at $25{ }^{\circ} \mathrm{C}, 50-60 \%$ humidity and $12 \mathrm{~h}$ day lighting/ $12 \mathrm{~h}$ dark for $24 \mathrm{~h}$.

5. Add aliquots from metallodrugs from stock solutions $(0.01 \mathrm{M})$ in the test tubes in order to incubate the bulbs with the metallodrugs, at 3 concentrations, with a range of for example 0.05 , 0.5 and $5 \mu \mathrm{M}$. The $\mathrm{IC}_{50}$ value of the metallodrugs towards the cancerous cell lines should be in this range of concentrations.

6. Incubate the Allium cepa bulbs (two per dose) with the metallodrugs for $48 \mathrm{~h}$.

7. After $48 \mathrm{~h}$, transfer the roots in tubes and add $5-10 \mathrm{ml} \mathrm{1:3}$ acetic acid-methanol solution, incubate for $24 \mathrm{~h}$ at $4{ }^{\circ} \mathrm{C}$. If the roots are not observed, they can be stored for a few days in $70 \%$ ethanol.

8. Transfer the roots into Eppendorf tubes with $1.0-1.5 \mathrm{ml} 6 \mathrm{~N} \mathrm{HCl}$ at $37^{\circ} \mathrm{C}$ for $10 \mathrm{~min}$.

9. Remove $\mathrm{HCl}$ and wash the roots for $1 \mathrm{~min}$ in distilled water.

10. Transfer the root tips into Eppendorf tubes and add 1.0-1.5 ml Schiff's reagent.

11. Incubate the root tips for $40 \mathrm{~min}$ at $37^{\circ} \mathrm{C}$.

12. Wash the root tips for $1 \mathrm{~min}$ in $45 \%$ acetic acid.

13. Remove the root caps from the well stained root tips with a razor blade. The length of roots treated should be about $0.5-2.0 \mathrm{~cm}$.

14. Immerse $1 \mathrm{~mm}$ of the meristematic in a drop of $45 \%$ acetic acid on a clean microscope slide. Put a coverslip onto mounting solution with one edge contacting the solution first; allow 
mounting solution to cover the entire surface of the coverglass, avoiding air bubbles. Squash into single cells using the eraser end of a pencil to apply pressure.

15. Seal the edges of the covering slip with nail polish.

16. The slide now is ready to observe under a fluorescence microscope. 


\section{bio-protocol

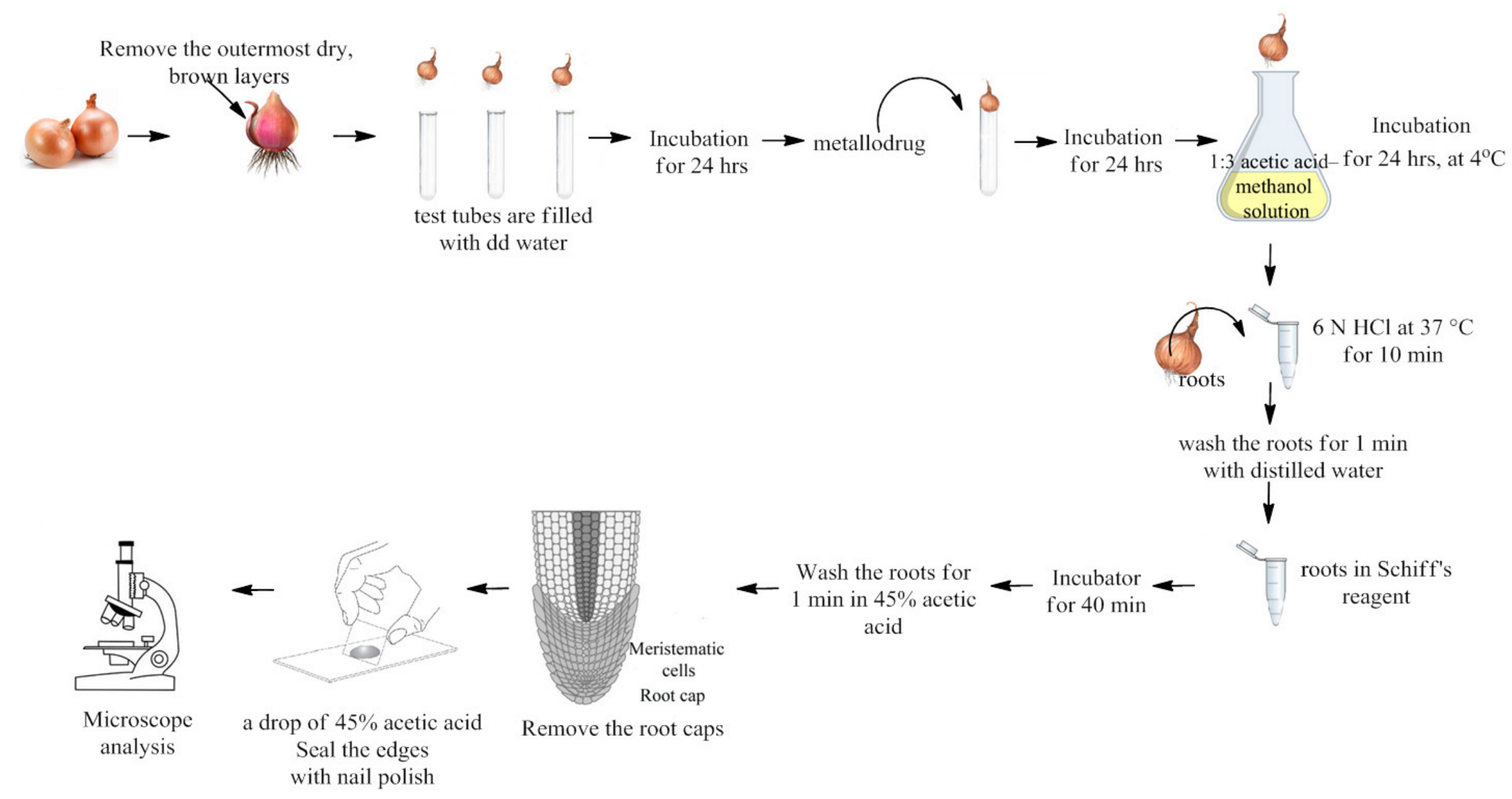

Figure 1. Experimental steps of Allium cepa assay 


\section{Data analysis}

A. Micronucleus assay

1. Count the number of micronucleated cells per 1,000 cells.

2. Calculate the percentage (\%) of micronucleus as the ratio of micronucleus to the 1,000 number of cells.

Note: The micronucleus was identified according to the previously established criteria: (1) the area of MN should correspond to 1/256 and 1/9 of the area of the main nuclei, (2) the shape of micronucleus should be round or oval, (3) the micronucleus should be readily distinguished from artifacts, (4) micronucleus is not linked or connected to the main nucleus, (5) micronucleus may touch, but not overlap the main nuclei and the micronuclear boundary should be distinguishable from the nuclear boundary and (6) the micronucleus should have the same staining intensity as the main nuclei.

3. Selected depiction of micronuclei formed in treated with an agent or not HCEC cells is shown in Figure 2 .
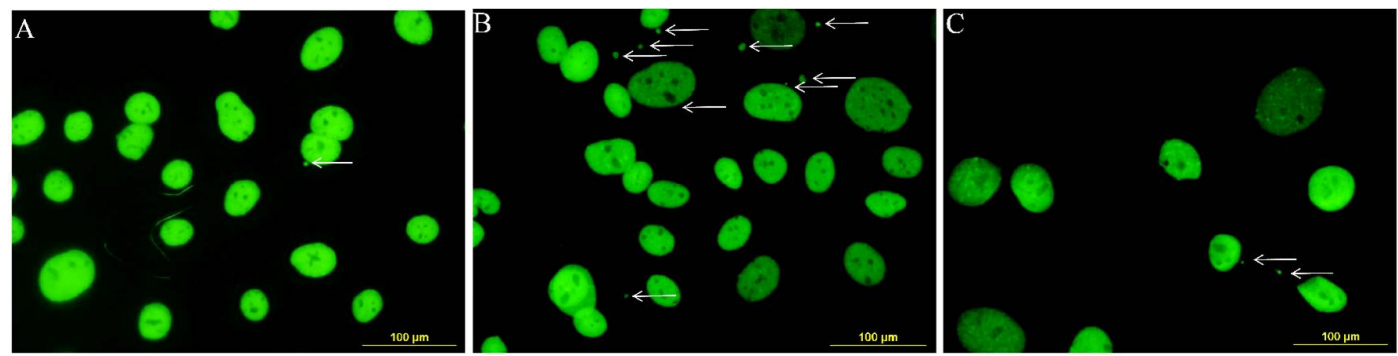

Figure 2. Selected snapshots of Micronucleus. Micronucleus which is formed within untreated (A) and treated by ciprofloxacin (B) and CIPAG, a conjugate of ciprofloxacin with silver(I) (C), HCEC cells; arrows indicate micronucleus in HCEC cells. The line bars correspond to $100 \mu \mathrm{m}$.

\section{B. Allium cepa assay}

1. The Mitotic index (MI), is the ratio between the total number of dividing cells in cell cycle (prophase, anaphase, metaphase, telophase) to the total number of cells. In order to evaluate the rate of the cellular division the microscopic parameter of the mitotic index (MI) was determined. All categories were analyzed by counting 1,800 cells per concentration (300 cells per slide, total of six slides, 3 slides per onion). The cytotoxicity levels of an agent can be determined by the increase or decrease in the Ml.

2. Chromosome aberrations (CA) are observed in the different phases of cell division (prophase, metaphase, anaphase and telophase). CA can be observed as chromosome bridges and breaks, chromosome losses, delays, adherence, multipolarity and C-metaphases. 
3. Nuclear abnormalities (NA) can be observed in the daughter cells as a similar structure to the main nucleus, but in a reduced size (lobulated nuclei, nuclei carrying nuclear buds, polynuclear cells, mini cells).

4. Micronucleus (MN) can be also observed in daughter cells as a similar structure but in reduced size to the mainnucleus.

5. Selected icons of Allium cepa meristematic cells in which normal prophase, anaphase, metaphase, telophase, chromosome aberrations, nuclear abnormalities and micronucleus are shown in the Figures 3-5.
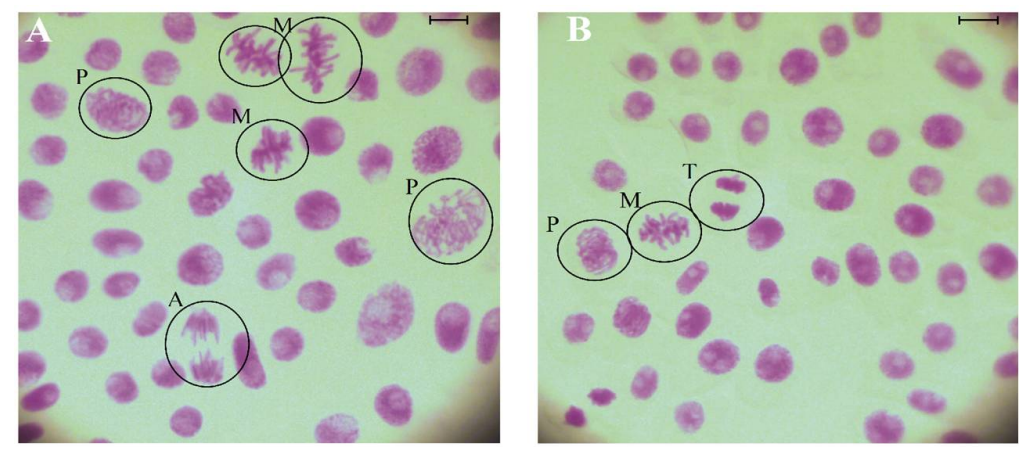

Figure 3. Normal phases of Allium cepa meristematic cells. A. Normal prophase (P), normal metaphase (M), normal anaphase (A) can be observed in Allium cepa meristematic cells. B. Normal prophase $(P)$, normal metaphase $(M)$ and normal telophase $(T)$ can be observed in Allium cepa meristematic cells. The line bars correspond to $2.5 \mu \mathrm{m}$.
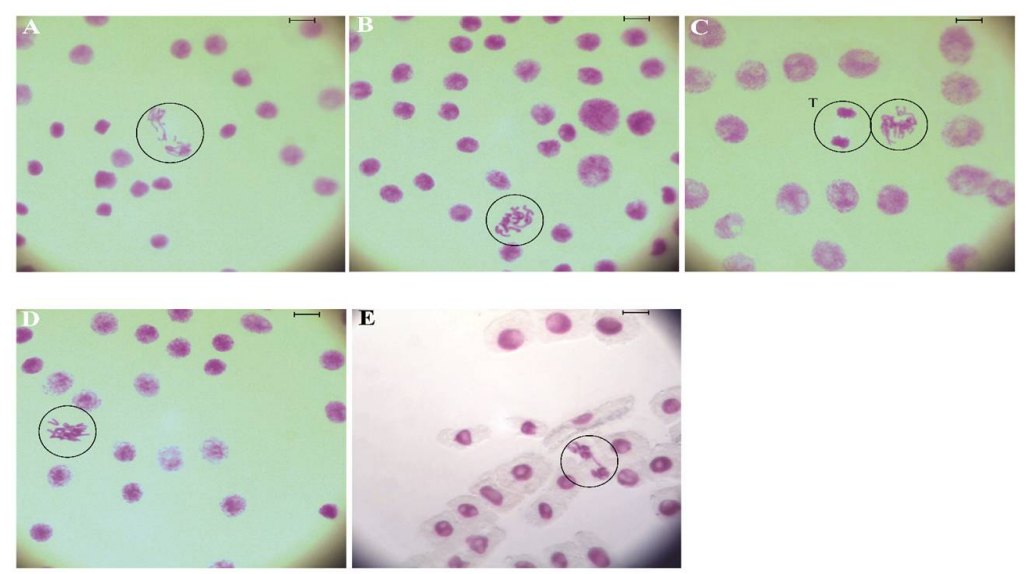

Figure 4. Chromosome aberrations observed in Allium cepa meristematic cells exposed to chemical agents. Chromosome loss and bridge at anaphase (A), C-metaphase (B), Chromosome adherence at metaphase (C), Chromosome loss at metaphase (D), Chromosome bridge at telophase $(\mathrm{E})$. The line bars correspond to $2.5 \mu \mathrm{m}$. 

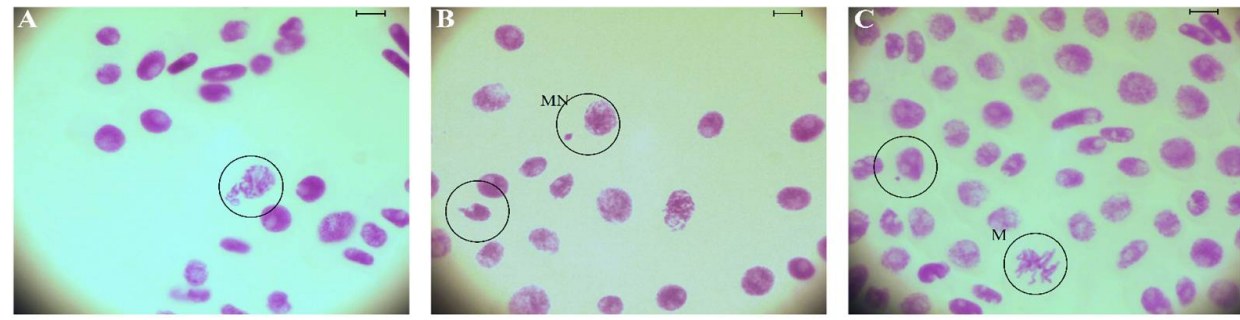

Figure 5. Nuclear abnormalities and micronucleus are observed in Allium cepa meristematic cells which are exposed to chemical agents. Prophase with synchronic nuclear bud (A), Interphasic nucleus with nuclear bud and Micronucleus in prophase (B), Micronucleated cell in interphase and normal metaphase $(M)(C)$. The line bars correspond to $2.5 \mu \mathrm{m}$.

\section{Acknowledgments}

The protocol for Micronucleus assay was adapted and modified from a previous study (Matsushima et al., 1999; Sohaebuddin and Tang, 2013). It was described in Banti et al., 2016; Sainis et al., 2016; Banti et al., 2018; Chrysouli et al., 2018a and 2018b; Latsis et al., 2018; Milionis et al., 2018; Polychronis et al., 2019; Banti et al., 2019.

The protocol for Allium cepa assay was adapted and modified from a previous study (Fiskesjó, 1988, Fiskesjó, 1993 and Fiskesjó, 1994). It was described in (Sainis et al., 2016; Chrysouli et al., 2018a and 2018b; Milionis et al., 2018; Stathopoulou et al., 2018).

This research has been co-financed by the European Union and Greek national funds through the Operational Program Competitiveness, Entrepreneurship and Innovation, under the call RESEARCH-CREATE-INNOVATE (project code:T1EDK-02990).

\section{Competing interests}

The authors declare no conflicts of interest or competing interests.

\section{References}

1. Banti, C. N., Papatriantafyllopoulou, C., Manoli, M., Tasiopoulos, A. J. and Hadjikakou, S. K. (2016). Nimesulide silver metallodrugs, containing the mitochondriotropic, triaryl derivatives of pnictogen; anticancer activity against human breast cancer cells. Inorg Chem 55(17): 8681-8696.

2. Banti, C. N., Papatriantafyllopoulou, C., Tasiopoulos, A. J. and Hadjikakou, S. K. (2018). New metalo-therapeutics of NSAIDs against human breast cancer cells. Eur J Med Chem 143: 1687-1701.

3. Banti, C. N., Hatzidimitriou, A. G., Kourkoumelis, N. and Hadjikakou, S. K. (2019). Diclofenac conjugates with biocides through silver(I) ions (CoMeD's); Development of a reliable model for 
the prediction of anti-proliferation of NSAID's-silver formulations. $J$ Inorg Biochem 194: 7-18.

4. Chrysouli, M. P., Banti, C. N., Kourkoumelis, N., Panayiotou, N., Markopoulos, G. S., Tasiopoulos, A. J. and Hadjikakou, S. K. (2018a). Chloro(triphenylphosphine)gold(I) a forefront reagent in gold chemistry as apoptotic agent for cancer cells. $J$ Inorg Biochem 179: 107-120.

5. Chrysouli, M. P., Banti, C. N., Milionis, I., Koumasi, D., Raptopoulou, C. P., Psycharis, V., Sainis, I. and Hadjikakou, S. K. (2018b). A water-soluble silver(I) formulation as an effective disinfectant of contact lenses cases. Mater Sci Eng C Mater Biol App/ 93: 902-910.

6. Fiskesjó, G. (1988). The Allium test--an alternative in environmental studies: the relative toxicity of metal ions. Mutat Res 197(2): 243-260.

7. Fiskesjó, G.(1993). Allium test I: A 2-3 day plant test for toxicity assessment by measuring the mean root growth of onions (Allium cepa L.). Environ Toxicol Water Qual 8: 461-470.

8. Fiskesjó, G. (1994).Allium Test II: Assessment of a chemical's genotoxic potential by recording aberrations in chromosomes and cell divisions in root tips of Allium cepa L. Environ Toxicol Water Qual 9: 235-241.

9. Latsis, G. K., Banti, C. N., Kourkoumelis, N., Papatriantafyllopoulou, C., Panagiotou, N., Tasiopoulos, A., Douvalis, A., Kalampounias, A. G., Bakas, T. and Hadjikakou, S. K. (2018). Poly organotin acetates against DNA with possible implementation on human breast cancer. Int J Mol Sci 19(7). pii: E2055.

10. Matsushima, T., Hayashi, M., Matsuoka, A., Ishidate, M., Jr., Miura, K. F., Shimizu, H., Suzuki, Y., Morimoto, K., Ogura, H., Mure, K., Koshi, K. and Sofuni, T. (1999). Validation study of the in vitro micronucleus test in a Chinese hamster lung cell line (CHL/IU). Mutagenesis 14(6): 569-580.

11. Milionis, I., Banti, C. N., Sainis, I., Raptopoulou, C. P., Psycharis, V., Kourkoumelis, N. and Hadjikakou, S. K. (2018). Silver ciprofloxacin (CIPAG): a successful combination of chemically modified antibiotic in inorganic-organic hybrid. J Biol Inorg Chem 23(5): 705-723.

12. Polychronis, N. M., Banti, C. N., Raptopoulou, C. P., Psycharis, V., Kourkoumelis, N. and Hadjikakou, S.K. (2019). Non steroidal anti-inflammatory drug (NSAIDs) in breast cancer chemotherapy; antimony(V) salicylate a DNA binder. Inorg Chim Acta 489: 39-47.

13. Sahu, S. C., Roy, S., Zheng, J., Yourick, J. J. and Sprando, R. L. (2014). Comparative genotoxicity of nanosilver in human liver HepG2 and colon Caco2 cells evaluated by fluorescent microscopy of cytochalasin B-blocked micronucleus formation. J Appl Toxicol 34(11): 1200-1208.

14. Sainis, I., Banti, C. N., Owczarzak, A. M., Kyros, L., Kourkoumelis, N., Kubicki, M. and Hadjikakou, S. K. (2016). New antibacterial, non-genotoxic materials, derived from the functionalization of the anti-thyroid drug methimazole with silver ions. J Inorg Biochem 160: 114-124.

15. Sohaebuddin, S.K. and Tang, L. (2013). A simple method to visualize and assess the integrity of lysosomal membrane in mammalian cells using a fluorescent dye. Methods Mol Biol 991: 25-31. 
16. Stathopoulou, M. K., Banti, C. N., Kourkoumelis, N., Hatzidimitriou, A. G., Kalampounias, A. G. and Hadjikakou, S. K. (2018). Silver complex of salicylic acid and its hydrogel-cream in wound healing chemotherapy. $J$ Inorg Biochem 181: 41-55.

17. Torres-Bugarín, O., Zavala-Cerna, M. G., Nava, A., Flores-García, A. and Ramos-Ibarra, M. L. (2014). Potential uses, limitations, and basic procedures of micronuclei and nuclear abnormalities in buccal cells. Dis Markers 2014: 956835. 